\title{
Coronary heart disease and mortality in middle aged men from different occupational classes in Sweden
}

\author{
Annika Rosengren, Hans Wedel, Lars Wilhelmsen
}

\begin{abstract}
In the Gothenburg primary prevention study $\mathbf{7 0 8 3}$ middle aged men were classified into five categories by occupational state. A retrospective analysis of the data showed that low occupational class was associated with slight increases in smoking rates, systolic blood pressure, serum cholesterol concentration, body mass index, and heart rate. Alcohol abuse was strongly associated with low occupational class. After a mean of 11.8 years' follow up the incidence of coronary heart disease was found to be strongly and inversely related to occupational class. For death from coronary heart disease this association fell just below significance when other risk factors were taken into account, but the inverse association between non-fatal myocardial infarction and occupational class persisted even in multivariate analysis. A weak but independent inverse relation was found between occupational class and fatal cancer. Mortality from all causes in the lowest occupational class was $12 \%$ compared with $6 \%$ in the highest class, and this difference could only partly be explained by other factors. After 10 years a subsample of the men were examined again. Risk factors had decreased in all occupational classes, but the changes in risk were not associated with occupational class.
\end{abstract}

Social class, defined by occupation, in Sweden is clearly related to the incidence of coronary heart disease.

\section{Introduction}

The association between low socioeconomic state and increased mortality in industrialised countries is well known. ${ }^{1-4}$ Furthermore, an association between coronary heart disease and low social class has been reported. ${ }^{5}$ Although social class differences in mortality and health are described from many countries, the availability of mortality data from Sweden is poor. In Sweden a well developed social security system ensures adequate food and housing for virtually all, medical care is supplied for everybody at low cost, and life expectancy is high by international standards. Under these circumstances differences in mortality between classes might be expected to decrease. In Norway, however, which in many respects is similar to Sweden, substantial differences in mortality persist, ${ }^{2}$ and similar findings have been reported from Finland. ${ }^{6}$ We examined the importance of socioeconomic factors for coronary heart disease and mortality in Sweden.

Nordic School of Public

Health, Gothenburg

Hans Wedel, PHD, professor

Correspondence to: $\mathrm{Dr}$ Rosengren.
The study population comprised the intervention group of the multifactor primary prevention trial. ${ }^{7}$
This trial was started in Gothenburg in 1970 and comprised all men in the city who were born from 1915 to 1925 except those born in 1923. The intervention group of 10000 men represented a random third of the men in the trial, with two control groups of 10000 men each. Altogether 7495 men aged $47-55$ (75\% of those invited) attended a screening examination, which took place from January 1970 to March 1973. Data on present occupation, physical activity at work and at leisure, smoking habits, diabetes, psychological stress (rated from 1 to 6 , with 6 representing continuous stress of long duration), and family history of cardiovascular disease were collected by postal questionnaire. At the screening examination blood pressure was measured after five minutes' rest with the subject seated. Body mass index was calculated as $\mathrm{kg} / \mathrm{m}^{2}$. Serum cholesterol concentration was determined according to standard laboratory procedures. Men who were found to be hypertensive, who had hypercholesterolaemia, or who smoked were referred to special intervention clinics.

Occupation was first coded according to the Swedish version of the International Standard Classification of Occupations. As this classification did not take social class into account, the data on occupation were reclassified later according to a new socioeconomic classification system elaborated by the Central Bureau of Statistics in Sweden. ${ }^{8}$ This classification, in the aggregated form used in this study, consists of five occupational classes: (1) unskilled and semiskilled workers, (2) skilled workers, (3) assistant non-manual employees and foremen in industrial production, (4) intermediate non-manual employees, and (5) employed and self employed professionals, higher civil servants, executives. Non-professional self employed men and men with disability pensions were not included. The analyses were restricted to the 7083 subjects who could be classified into classes 1 to 5 . Data on alcohol abuse ${ }^{9}$ and marital state were collected, with special permission, from official registers. No particular attempt was made to exclude subjects with prior disease.

All subjects were followed up until March 1983 (mean follow up period 11.8 years). All cases of nonfatal myocardial infarction and stroke in the city were recorded according to specific criteria. ${ }^{1011}$ Death certificates were collected continuously and the Swedish national register on deaths due to specific causes was matched against a computer file for all the men in the study. Mortality due to specific causes was coded by two doctors according to the International Classification of Diseases (8th revision). Total coronary heart disease was defined as all men with either non-fatal myocardial infarction or death attributed to coronary heart disease during follow up.

Ten years after the initial screening the survivors of a subsample of the intervention group who were still 
living in the city (2144) were invited for a further examination to review changes in the pattern of risk factors. We used data on occupational class available for 1271 subjects who had attended both examinations. No significant differences in the pattern of risk factors between the intervention group and two equally large control groups was detected. ${ }^{7}$ Nor were there any differences in outcome, which means that any changes brought about by the intervention must have taken place among the general population as well.

Possible associations between continuous or graded variables, or both, were tested with Pitman's nonparametric permutation test. ${ }^{12}$ Adjusted odds ratios were calculated by logistic regression. ${ }^{13}$

\section{Results}

Table I shows baseline variables related to occupational class. Systolic blood pressure, serum cholesterol concentrations, body mass index, and heart rate were all slightly but significantly inversely related to occupational class $(p<0.007)$. Smoking was slightly more prevalent in the lower occupational classes $(54.0 \% v$ $47.5 \%, \mathrm{p}<0.001)$. There was a positive correlation between psychological stress and occupational class, with more subjects in the higher classes having experi-

TABLE I-Risk factors and other characteristics at baseline in relation to occupational class

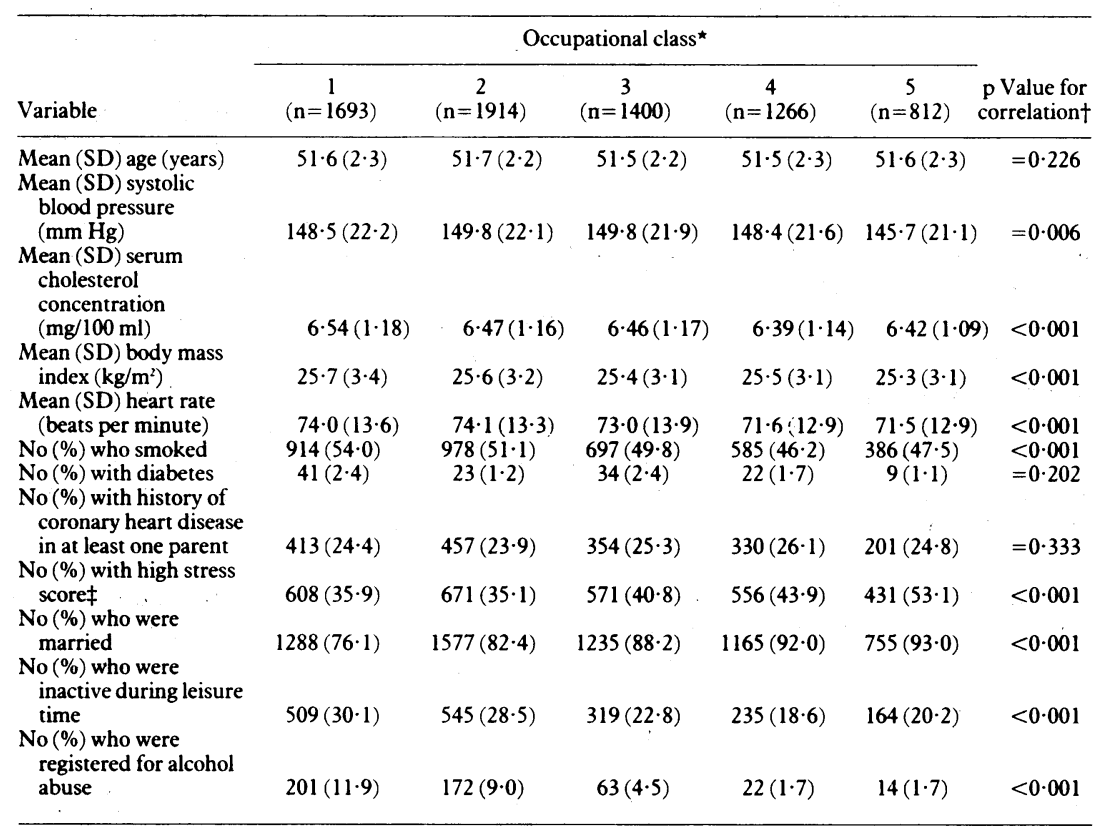

$\star 1$. Unskilled and semiskilled workers; 2 . skilled workers; 3 . assistant non-manual employees and foremen in industrial production; 4 . intermediate non-manual employees; 5 . employed and self-employed professionals, higher civil servants, executives.

tTested for trend with Pitman's non-parametric test.

$\ddagger$ More than one period of stress during the past five years.

TABLE II -Number (percentage) of men for each end point during $11 \cdot 8$ years' follow up by occupational class

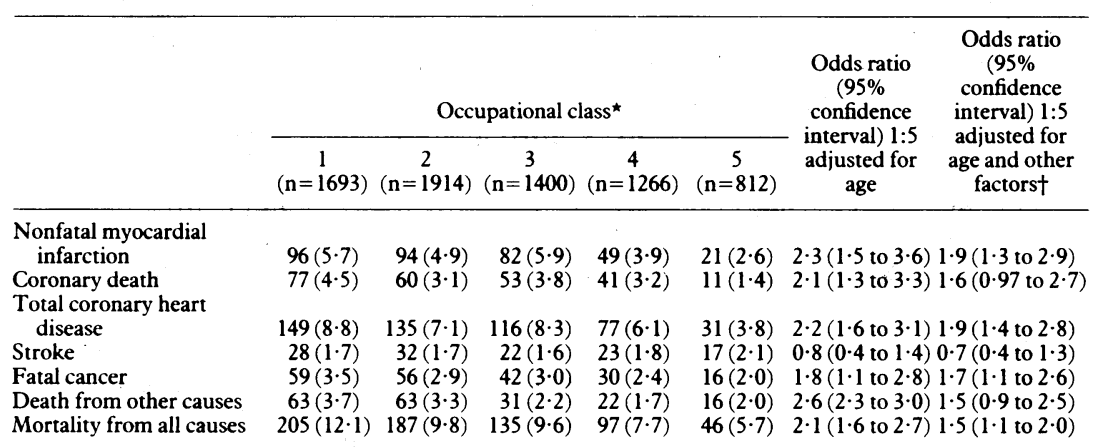

${ }^{\star}$ Definitions as for table $I$.

†Base-line variables entered into the model: systolic blood pressure, serum cholesterol concentration, smoking habits, heart rate, body mass index, family history of coronary heart disease, diabetes, leisure time physical activity, stress score, marital state, and registration for alcohol abuse.

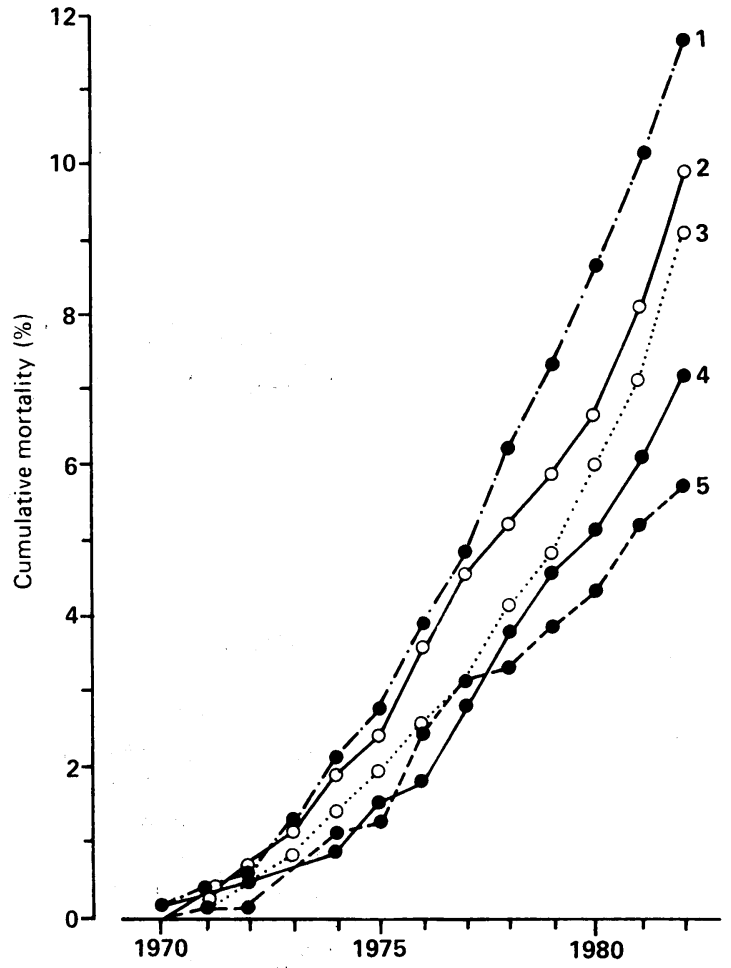

Cumulative mortality (\%) during follow up in relation to occupational class. For definitions of classes 1 to 5 see table I

enced periods of stress $(53 \cdot 1 \% v 35.9 \%, \mathrm{p}<0.001)$. Significantly more subjects in the higher occupational classes were married at the time of the screening examination $(93.0 \% v 76 \cdot 1 \%, \mathrm{p}<0.001)$. Registration for alcohol problems was strongly associated with low occupational class $(11.9 \%$ v $1.7 \%)$.

Table II shows the strong inverse relation between occupational class and all coronary end points. The rate of coronary heart disease in occupational class 1 during follow up was more than twice that of occupational class $5(8.8 \% v 3.8 \%)$. For non-fatal myocardial infarction and total coronary heart disease the odds ratios for the lowest in relation to the highest class were only slightly reduced when other risk factors were taken into account. Coronary death, however, was not independently associated with occupational class, even though the lower limit of the confidence interval was close to one. The incidence of stroke (fatal and nonfatal combined) during follow up was similar in all classes. Deaths from cancer and all cause mortality were significantly and inversely associated with occupational class. The figure shows the cumulative mortality of the different classes and shows a continuously widening gap between the highest and lowest occupational classes over time.

Table III gives the data from the 10 year follow up. Risk factors had decreased in all occupational classes, but there was no consistent relation between the magnitude of the changes and occupational class.

\section{Discussion}

Social class, defined by occupation, is admittedly a crude and arbitrary concept as it groups together people from a wide variety of occupations subject to varying occupational hazards and with different backgrounds and education. In this study no data on income or education were available so the classification was based on occupation alone and rests on a preconceived notion of rank in society without any more theoretical considerations. The disadvantage of earlier classification attempts in Sweden was probably that they were either too crude, as in the widely used three graded social group classification, or were not 
TABLE III - Risk factors in subsample of 1271 men at baseline and at follow up screening examination after 10 years by occupational class at initial screening

\begin{tabular}{|c|c|c|c|c|c|c|}
\hline & \multicolumn{5}{|c|}{ Occupational class ${ }^{\star}$} & \multirow[b]{2}{*}{$\begin{array}{l}\mathrm{p} \text { Value for } \\
\text { correlation } \dagger\end{array}$} \\
\hline & $\begin{array}{c}1 \\
(\mathrm{n}=277)\end{array}$ & $\begin{array}{c}2 \\
(\mathbf{n}=314)\end{array}$ & $\begin{array}{c}3 \\
(\mathbf{n}=255)\end{array}$ & $\begin{array}{c}4 \\
(n=261)\end{array}$ & $\begin{array}{c}5 \\
(n=164)\end{array}$ & \\
\hline \multicolumn{6}{|l|}{ Mean baseline systolic } & NS \\
\hline $\begin{array}{l}\text { Mean follow up systolic } \\
\text { blood pressure } \\
(\mathrm{mm} \mathrm{Hg})\end{array}$ & $143 \cdot 3$ & $145 \cdot 1$ & $143 \cdot 1$ & $142 \cdot 4$ & 139.8 & $=0.034$ \\
\hline Change $(\%)$ & $-3 \cdot 0$ & $-2 \cdot 2$ & -4.6 & $-3 \cdot 8$ & -3.8 & NS \\
\hline $\begin{array}{l}\text { Mean baseline serum } \\
\text { cholesterol } \\
\text { concentration } \\
(\mathrm{mg} / 100 \mathrm{ml})\end{array}$ & 6.59 & $6 \cdot 30$ & 6.51 & $6 \cdot 32$ & $6 \cdot 32$ & $=0.031$ \\
\hline $\begin{array}{l}\text { Mean follow up serum } \\
\text { cholesterol (mg/100 } \\
\mathrm{ml})\end{array}$ & & & & & & \\
\hline $\begin{array}{l}\mathrm{ml}) \\
\text { Change (\%) }\end{array}$ & $\begin{array}{l}6.09 \\
-7 \cdot 6\end{array}$ & $\begin{array}{r}\quad 6 \cdot 02 \\
-4 \cdot 4\end{array}$ & $\begin{array}{l}6 \cdot 02 \\
-7 \cdot 5\end{array}$ & $\begin{array}{l}6 \cdot 00 \\
-5 \cdot 1\end{array}$ & $\begin{array}{l}5 \cdot 83 \\
-7 \cdot 8\end{array}$ & $\begin{array}{l}=0.014 \\
\text { NS }\end{array}$ \\
\hline $\begin{array}{l}\text { No }(\%) \text { who smoked at } \\
\text { baseline } \\
\text { No }(\%) \text { who smoked at }\end{array}$ & $131(47 \cdot 3)$ & $158(50 \cdot 3)$ & $104(40 \cdot 8)$ & $113(43 \cdot 3)$ & $64(39 \cdot 0)$ & $=0.022$ \\
\hline $\begin{array}{l}\text { follow up } \\
\text { Change }(\%)\end{array}$ & $\begin{array}{l}96(34 \cdot 7) \\
-26 \cdot 6\end{array}$ & $\begin{array}{l}95(30 \cdot 3) \\
-39 \cdot 8\end{array}$ & $\begin{array}{l}66(25 \cdot 9) \\
-36 \cdot 5\end{array}$ & $\begin{array}{l}69(26 \cdot 4) \\
-39 \cdot 0\end{array}$ & $\begin{array}{l}41(25 \cdot 0) \\
-36 \cdot 4\end{array}$ & $\begin{aligned}= & 0 \cdot 014 \\
& \text { NS }\end{aligned}$ \\
\hline
\end{tabular}

$\star$ Definitions as in table $\mathbf{I}$.

†Tested for trend with Pitman's non-parametric permutation test.

hierarchical, as in the official analyses from the Central Bureau of Statistics in Sweden. Surveys that used the three graded scale generally showed small differences in mortality between the social groups. ${ }^{14} \mathrm{~A}$ recent official report, however, states that substantial differences between non-manual and manual occupations have developed over the period $1970-80 .{ }^{15}$

More information exists on symptoms of disease, longstanding illness, and functional impairment in relation to socioeconomic factors. Symptoms of cardiovascular disease, impaired working capacity, functional disability, impairment of hearing and vision, lack of teeth, anxiety, and sleeping problems have all been reported more often among unskilled workers than among higher officials in different surveys. ${ }^{16}$

Our data suggest that the impact of socioeconomic factors is far from negligible. If the low mortality in the highest occupational class had prevailed for the entire study population (participants and non-participants) fewer than 600 men would have died during the follow up period, instead of nearly $1300-$ a net loss of more than 700 lives. The results from this study, however, must be interpreted with caution. The classification used was developed several years after the screening examination, and the classification of the men into the different categories was also done at a later date, though the data on occupation were collected at the first screening. This also means that there was no prior hypothesis, and the results must be seen accordingly. Also the data are not consistent with earlier Swedish investigations even if more recent reports seem to confirm the results of our study. More national research on this subject is certainly warranted.

The non-participation rate of $25 \%$ in our study is of similar magnitude to that in other general population studies. Even so, it is not negligible, as those who did not come to the examination tended to have worse social problems and more alcohol abuse than those who took part in the study. ${ }^{17}$ Also the mortality among the non-participants was about double that of the participants, and non-participants had a higher rate of coronary heart disease, albeit confined to fatal events. Occupation among non-participants could not be established, but probably their inclusion in the study would have resulted in a steeper gradient in the relation between coronary heart disease and mortality, on the one hand, and occupational class, on the other.

An inverse relation between coronary heart disease and social class has been described in several studies, mostly from Anglo-Saxon countries and also from Norway and Finland. ${ }^{2518-23}$ In Sweden data from national surveys and hospital inpatient registers have suggested an association between hospital care for coronary heart disease and employment in occupations combining hectic work with few opportunities to learn new things. ${ }^{24}$ In addition, the admission of patients to hospital with coronary heart disease was found to be associated with shift work and monotony. ${ }^{25}$ So far there has been a lack of data from prospective studies in Sweden. The differences found in our study on the incidence of coronary heart disease were quite large and could only be explained to a small extent by other factors. The magnitude of the differences found agreed with the unadjusted Oslo data. ${ }^{2}$

Lifestyle and the uneven distribution of established risk factors for coronary heart disease may be the most obvious explanations for the differences between social classes. In the Whitehall study the proportion of smokers increased substantially in the lower employment grades, 5 a finding not replicated in our study, where the increase was only slight. Smokers from lower occupational classes tended to smoke less tobacco than men from higher classes, and when smoking was analysed as a graded instead of as a dichotomous variable no overall association between smoking and occupational class was seen. A Swedish national survey of smoking habits conducted in 1963 did not show any distinct cifference in smoking habits between different occupational classes. ${ }^{26}$

Alcohol abuse was much more common among the lower occupational groups. In previous surveys from the same study population we found that alcohol abuse was unrelated to non-fatal myocardial infarction but was a strong risk factor for coronary death. ${ }^{9}$ As alcohol abuse was not associated with non-fatal myocardial infarction this cannot explain the increased incidence of non-fatal myocardial infarction in manual workers. Even though coronary death was not independently associated with occupational class, to discount entirely a possible independent role for socioeconomic factors in relation to coronary death is not justified as registration is a marker of both low socioeconomic state and alcohol abuse. Also the lower limit of the confidence interval, after taking possible confounders into consideration, was close to 1 . Occupational class was independently associated with total mortality even after controlling for alcohol abuse.

Subjects from lower occupational classes tended to have higher systolic blood pressure, but the differences, though significant, were small and could not account for the increase in coronary heart disease. Differences in blood pressure related to socioeconomic state have been described in other reports. ${ }^{52023}$ The relation between serum cholesterol concentration and social class is less consistent. Contrary to our findings, an increase in concentration with higher occupational grade was found in the Whitehall study. ${ }^{5}$ Recently the level of education has been found to be strongly and inversely correlated with serum cholesterol concentration in a Norwegian cross sectional study. ${ }^{27}$ After 10 years' follow up systolic blood pressure, serum cholesterol concentration, and smoking had decreased among those who were re-examined. This could not be attributed to the intervention as such, as a similar reduction could also be seen among the controls.? Awareness of risk factors seems to have risen during this period among the general population and the medical profession. The decrease has been confirmed by recent results from examinations of younger men in Gothenburg (unpublished data).

As in the Whitehall study, we found differences with respect to height, but the differences between lower and higher occupational classes were less: men in occupational class 5 were, on average, $3 \mathrm{~cm}$ taller than those in occupational class 1 (data not shown). Height may reflect genetic constitution as well as nutritional 
factors during childhood. The men in our study were born during the first world war or in the years immediately afterwards. Even though Sweden did not play an active part in the war, material deprivation prevailed for some of the population during this period, particularly in the cities. In Norway a signifcant positive correlation was found between county age adjusted mortality from coronary heart disease and county infant mortality during the early years of the same cohorts, which suggests that poverty in childhood followed by prosperity may be a risk factor for coronary heart disease. ${ }^{28}$ Similar findings were reported from Britain. ${ }^{29}$ These findings could offer an explanation of the change in the social class distribution of coronary heart disease. ${ }^{18}$ Various other causes of death are associated with childhood poverty, which suggests that probably several factors are operating. ${ }^{30}$

Circumstances differ among occupational classes. Material deprivation in itself is, however, unlikely to be important as, our study population would have been comfortably off during most of their adult lives. Nevertheless, some aspects of life circumstances such as occupational hazards are not evenly distributed. Accidents at work during follow up were not common, but the small excess of deaths from cancer in the lower occupational classes may perhaps be attributed to work conditions even if dietary factors may be more important. ${ }^{31}$ Men in the lower occupational classes had less psychological stress than others, though this association cannot be taken at face value, as an abstract concept like stress might be recognised more readily among better educated people.

Another variable in circumstances concerns social networks. Several studies have shown a higher mortality among people who lack social and community ties than among those with more contacts. ${ }^{32}$ In our study marital state was clearly associated with occupational class, and both factors were independently associated with total mortality, whereas only occupational class was independently associated with the incidence of coronary heart disease. Marital state is, however, only one indicator of social support, and probably other network factors are also unevenly distributed among the different occupational classes.

As only present occupation was registered mobility between classes could not be studied. Furthermore, no data on class of origin were collected. Consequently downward drifts in occupational class secondary to selective mechanisms could not be controlled for There was no levelling off, however, in the mortality differentials with time, which probably would have occurred if there had been a major selection due to preexisting illness. When men with a prior history of myocardial infarction were removed from the analyses it made no difference to the results.

In conclusion, we found a clear inverse relation between occupational class and the incidence of coronary heart disease and total mortality entailing many excess deaths in the lower socioeconomic strata. Possible reasons include differences in patterns of risk factors, and in lifestyle, effects of occupational hazards, and low social support, but no clear answer to why class differences persist has been forthcoming. The magnitude of the problem certainly warrants further study, not least from a preventive point of view.

1 Black D. Inequalities in health: report of a working group. London: HMSO, 1980.

2 Holme I, Helgeland A, Hjermann I, Leren P, Lund-Larsen PG. Four-year mortality by some socioeconomic indicators: the Oslo study. 7 Epidemiol mortality by some socioeconomic

3 Seltzer CC, Jablon S. Army rank and subsequent mortality by cause: 23 -year follow-up. Am $\mathcal{F}$ Epidemiol 1977; 105:559-66.
4 Pearce NE, Davis PB, Smith AH, Foster FH. Mortality and social class in New Zealand. I: overall male mortality. $N$ Z Med $\mathcal{F}$ 1983;96:281-5.

5 Marmot MG, Shipley MJ, Rose G. Inequalities in death - specific explanations of a general pattern? Lancet $1984 ; \mathrm{i}: 1003-6$.

6 Koskenvuo M, Sarna S, Kaprio J. Mortality by marital status and social class in Finland during 1969-71. Scand f Soc Med 1978;6:137-43.

7 Wilhelmsen L, Berglund G, Elmfeldt D, et al. The multifactor primary preventive trial in Göteborg, Sweden. Eur Heart $f$ 1986;7:279-88.

8 Statistics Sweden. Swedish socio-economic classification. Stockholm: Statistics Sweden, 1982.

9 Rosengren A, Wilhelmsen L, Pennert K, Berglund G, Elmfeldt D. Alcohol intemperance, coronary heart disease and mortality in middle-aged Swedish intemperance, coronary heart disease and
men. Acta Med Scand 1987;222:201-13.

10 Elmfeldt D, Wilhelmsen L, Tibblin G, Vedin A, Wilhelmsson C, Bengtsson C. Registration of myocardial infarction in the city of Göteborg, Sweden. f Chronic Dis 1975;28:173-86.

11 Harmsen P, Berglund G, Larsson O, Tibblin G, Wilhelmsen L. Stroke registration in Göteborg, Sweden 1970-75. Acta Med Scand 1979;206: $337-44$.

12 Bradley JV. Distribution-free statistical tests. Englewood Cliffs, New Jersey: Prentice-Hall, 1968:68-86.

13 Kleinbaum DG, Kupper LL, Morgenstern H. Epidemiologic research: principles and quantitative methods. Belmont, California: Lifetime Learning Publications, 1982:422-32.

14 Lundberg O. Class and health: comparing Britain and Sweden. Soc Sci Med 1986;23:511-7

15 Anonymous. Folkhälsorapport 1987. Stockholm: Allmänna Förlaget, 1987.

16 Statistics Sweden. Living Conditions. Ill Health and Medical Care. Stockholm: Statistics Sweden, 1985. (Report No 42.)

17 Rosengren A, Wilhelmsen L, Berglund G, Elmfeldt D. Non-participants in a general population study of men, with special reference to social and general population study of men, with special referen

18 Marmot MG, McDowall ME. Mortality decline and widening social inequalities. Lancet 1986;ii:274-6.

19 Pocock SJ, Shaper AG, Cook DG, Phillips AN, Walker M. Social class differences in ischemic heart disease in British men. Lancet 1987;ii:197-201. 20 Liu K, Cedres LB, Stamler J, et al. Relationship of education to major risk factors and death from coronary heart disease, cardiovascular diseases and all causes. Findings of three Chicago epidemiologic studies. Circulation 1982;66: 1308-14.

21 Pearce NE, Davis PB, Smith AH, Foster FH. Mortality and social class in New Zealand II: male mortality by major disease groupings. $N Z$ Med $\mathcal{J}$ 1983;96:711-6.

22 Koskenvuo M, Kaprio J, Kesäniemii A, Sarna S. Differences in mortality from ischemic heart disease by marital status and social class. $\mathcal{F}$ Chronic Dis 1980;33:95-106.

23 Dobson AJ, Gibberd RW, Leeder SR, O'Connell DL. Occupational differences in ischemic heart disease mortality and risk factors in Australia. $A m \mathcal{J}$ Epidemiol 1985;122:283-90

24 Alfredsson L, Karasek R, Theorell T. Myocardial infarction risk and psychosocial work environment: an analysis of the male Swedish working force. Soc Sci Med 1982;16:463-7.

25 Alfredsson L, Spetz. CL, Theorell T. Type of occupation and near-future hospitalization for myocardial infarction and some other diagnoses. Int $\mathfrak{f}$ Epidemiol 1985;14:378-86.

26 SCB Utredningsinstitutet. Rökvanori Sverige. En postenkätundersökning våren 1963. Stockholm: SCB Utredningsinstitutet, 1965

27 Jacobsen BK, Thelle DS. Risk factors for coronary heart disease and level of education: the Tromso heart study. Am $\mathcal{F}$ Epidemiol 1988;127:923-32.

28 Forsdahl A. Are poor living conditions in childhood and adolescence an important risk factor for arteriosclerotic heart disease? British fournal of Preventive and Social Medicine 1977;31:91-5.

29 Barker DJP, Osmond C. Infant mortality, childhood nutrition, and ischaemic heart disease in England and Wales. Lancet 1986; i: 1077-81.

30 Barker DJP, Osmond C. Inequalities in health in Britain: specific explanations Barker DJP, Osmond C. Inequalities in health in Britain:
in three Lancashire towns. Br Med f 1987;294:749-52.

31 Doll R, Peto R. The causes of cancer. INCI 1981;66:1191-308.

32 Berkman LF, Syme L. Social networks, host resistance and mortality: a nineyear follow-up study of Alameda County residents. Am $\mathcal{J}$ Epidemiol 1979;109:186-204.

(Accepted 26 September 1988

\section{Corrections}

\section{Sustained compression and healing of chronic} venous ulcers

An editorial error occurred in this paper by Mr Stephen D Blair and others (5 November, p 1159). In the third sentence of the second paragraph under Patients and methods "(Elset; Seton)" was transposed. The sentence should have read: "This was compressed with a standard crêpe bandage, which preserved the elastic energy of the main compression bandage (Elset; Seton) and made application easier."

\section{Damp housing and childhood asthma: validation of} reporting of symptoms

Two editorial errors occurred in this paper by Dr D P Strachan (12 November, $p$ 1223). In the fourth paragraph of the Results " $83 \%(58 / 700) "$ should read " $8 \cdot 3 \%(58 / 700)$," and the sixth paragraph of the Discussion should start, "Lack of sensitivity and random errors in the test procedure may have reduced the power of the study to detect a true relation between reported mould and bronchial lability. The negative findings, therefore, do not exclude an association." 